\title{
ON SOME ANOMALIES IN THE DENTITION OF PHOCA HISPIDA
}

BY

\author{
EINAR LÖNNBERG.
}

(With 6 Figures)

Variation with regard to the dentition is perhaps a more common occurrence among the Seals than among most other groups of Mammals. It is quite probable, that this stands in connection with the more or less reduced condition of the teeth of these animals. The variation in the dental formula can make itself known in several different ways. In his valuable book "Materials for the Study of Variation" BATESON has recorded a great number of dental anomalies among Pinnipedia, concerning in one case the incisors, and in the others the premolar-molar series. Although the author quoted worked with material from different parts of the world and belonging to various genera and species, he does not appear to have known any Phoca hispida with abnorm dentition. Already 1878 the Danish Zoologist SAHLERTZ had, however, the opportunity of reporting about such and found that among 76 skulls of this species not less than 5 presented greater or smaller anomalies. One of these was purely pathological, in the other cases there were found one or two supernumerary premolars or molars.

Some time ago I had the pleasure of receiving from my friend Dr. O. NoRDQVIST, Director of the Fisheries Bureau, several lower jaws of as well Phoca hispida as Ph. vitulina, which had been delivered for receiving bounties. It is especially the former of these, which are of interest with regard to their dentition because they display very great anomalies. In most cases it is the premolars and molars, which are subjected to variation, as will be described below, but there is also a specimen, which presents a most interesting anomaly with regard to the incisors. It has namely not less than six well developed incisors. The animal has been rather young when killed, with a length of the lower jaw amounting to only $85 \mathrm{~mm}$. (115-122 mm. in old animals). In consequence of the youth the incisors are crowded, but they are all of nearly equal size and none of them gives the impression of being on the way to become suppressed. The arrangement is, as the photographic reproduction (fig. 1) proves, regular on both sides, and the crowding has resulted in the pressing backwards of $i_{2}$ out of the row, somewhat behind the others. It is of interest to state, that such an arrangement, i. e. the pressing backwards of $i_{2}$ is fully in accordance with the situation of the incisors in the Otters and also in musteline and viverrine Carnivora etc. generally in such cases, when the incisors are crowded.

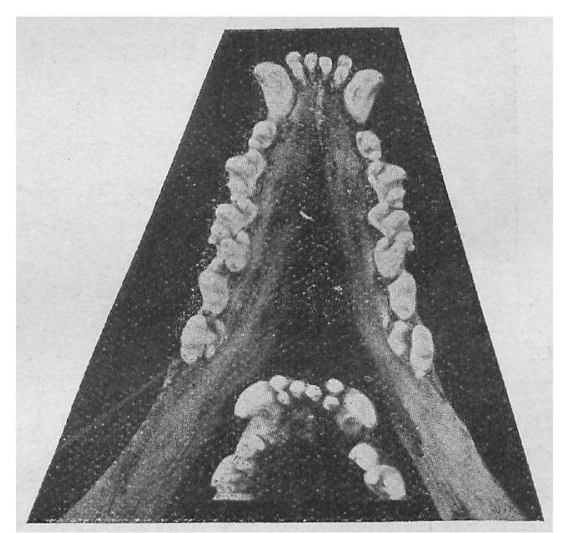

Fig. 1. Part of the lower jaw of a young Phoca hispida from Umeă, northern Sweden, showing six incisors. The lower figure is of the same jaw, but photographed in a somewhat different position to show more precisely the situation of the incisors.

Such an arrangement may thus be termed normal. It is also to be observed, that in a normal young Phoca hispida with four incisors in the lower jaw $i_{2}$ to begin with often, if not always, does not sit on a level with $i_{3}$ but somewhat further back. When the animals are grown up all four incisors usually 
form a straight line, but sometimes the $i_{2}$ retains it somewhat posterior situation. This is $\mathrm{f}$. $\mathrm{i}$. the case in a specimen, in which the lower jaw has a length of $117 \mathrm{~mm}$, and which is so old, that the premolars are rather strongly worn. Thus the position of $i_{2}$ must be regarded as the normal one even for this Seal. But it is the presence of the otherwise long lost $i_{1}$, which is the very remarkable thing in this case. This tooth is not to be found in any Pinnipedia except in the young Walrus. In Phoca hispida and its allies it has become lost so long time ago that, according to TeNow's investigations (1875), it is not even present in the milk-dentition. It is thus not possible to explain the presence of both $i_{1}$ in this specimen as retained milk-teeth, and against such a supposition speaks also their size, which, as already mentioned, is equal to that of the other normal incisors. The only possible explanation is thus, that these teeth constitute an extremely rare example of the reappearance of an organ which already was entirely lost innumerable generations ago. - The specimen in question is from the coast outside the city of Umeä, about $45^{\circ}$ n. lat.

The anomaly with regard to the incisors in a Seal described by BATESON consists in a reduction in number of- these teeth in a Phoca barbata, which had only 4 incisors in the upper and 2 in the lower jaw, and also in the loss of an upper incisor on one side of another specimen. This, although interesting in itself, stands, however, in accordance with the general evolution of the dentition of the seals, which tends to a reduction in the number of the incisors. It is thus not by far so very remarkable as the reappearance of $i_{1}$ in the Phoca hispida from Umea.

In another young Phoca hispida from the archipelago outside Husum, northern Sweden there is an anomaly with regard to the canines. On both sides of the lower jaw at the base of the canine on its inner posterior side there is a free point about $2 \mathrm{~mm}$. in length and looking like the tip of another canine tooth. When the alveole is broken up, it becomes however apparent that this tip is attached to the canine itself and basally coalesced with the same. When the canine tooth was split longitudinally it was even found, that the pulpcavity of the canine stands in open connection with that of the accessory tip itself. As well from the general appearance, and size as from the situation on the inner and posterior side of the canine it is evident that this accessory tip cannot represent the remains of a milk-canine. The only explanation is that it has originated by a partial reduplication of the anlage of the permanent canine, which has taken place symmetrically on both sides.

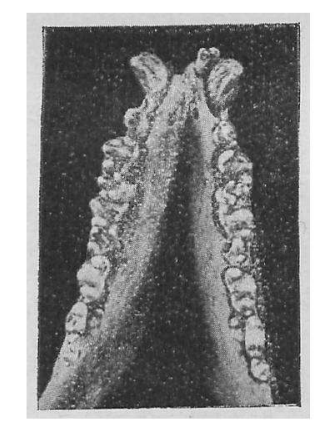

Fig. 2. Anterior portion of the lower jaw of a young Phoca hispid from Hudiksvall, Sweden, showing canine like first premolar on the left side, supernumerary second molars $\left(m_{2}\right)$ on premolars.

look to be normal, but a closer examination reveals, that the third and fourth premolars are fused together at their adjoining ends so as to form a single long tooth with three roots, the middle one of which has been formed by the concrescence of the posterior root of the third and the anterior one of the fourth premolar. The number of cusps is, what it ought to be by adding together the normal number of both the fused teeth, viz. eight. They have also retained their position with the exception of the most anterior cusp of the fourth premolar which has been pushed out of the row and sits on the inner side of the tooth. It is of interest to state that this 
concrescence of these premolars has taken place in absolutely the same way on both sides, and that both the double teeth are absolutely alike in every detail including the increase in size of the third cusp (counting from the anterior end) of the third premolar, which has become larger than the normal middle cusp. The length of the double teeth is $11,5 \mathrm{~mm}$., that of the adjoining simple ones $7 \mathrm{~mm}$.

Such a concrescence of two premolars is not a singular occurrence. There is another specimen from the island Holmön outside Umeå, in which the same thing has taken place. It is in this specimen, however, somewhat more complicated, because the number of teeth is increased above the normal one. Thus on the right side there are five teeth in a regular row in spite of the fact that one of them evidently is double with three roots and consequently composite of two normal teeth. An additional tooth has thus been developed here and this must be regarded as a second molar. On the left side the regular toothseries also consists of five teeth, if the double one is counted as one, but in addition to them there are two smaller teeth extra ordinem. As the by concrescence double teeth on either side are the next last of the series with three ordinary premolars in front of them, they must have originated by the fusion of the last premolar and the first molar. Their appearance is nearly similar

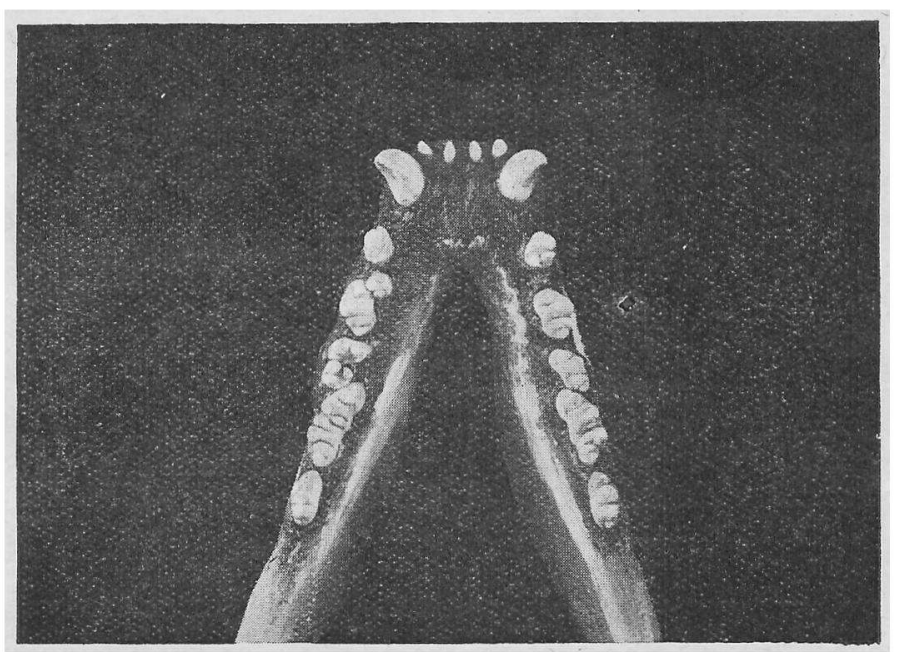

Fig. 3. Dental portion of the lower jaw of an adult Phoca hispida from the island Holmön outside Umea, northern Sweden, showing on both sides a double tooth with three roots, and on the left side accessory teeth.

to those just described above, especially on

the left side, where the number of cusps also are eight, but on the right the cusps are reduced to seven. This mandible is figured in fig. 3.

In a corresponding manner as a lengthening of the teeth can be effected by the concrescence of two teeth of the normal series, a broadening of the teeth can be produced by the fusion of a normal tooth with an extra or accessory tooth on its inner (median) side. Such a thing is illustrated by fig. 4, which represents the lower jaw of a Phoca hispida from Fredals archipelago, Stockholms gouvernment district. It is plainly seen in this example that the third premolar, which has its quite regular appearance with its four cusps as usual, on its inner side is provided with a peculiar looking heel or talon carrying one well developed and a small cusp. This talon, which is supported by a separate root, is no doubt to be understood as an accessory tooth (cf. below), which has become fused with the normal third premolar. As will be shown below, it is rather a comparatively common occurrence, that accessory teeth are found on the median side of the regular series. It is even in this case a full symmetry with a similar product of concrescence on both sides of the jaw.

One example of an increase of the number of the regular toothseries by the addition of a sixth tooth, a second molar has already been mentioned above (specimen from Holmön, fig. 3). There are several such similar cases. For instance the specimen (fig. 2), which has been mentioned above in consequence of its first premolar being like a canine in shape, has on both sides a small second molar with a main cusp and a

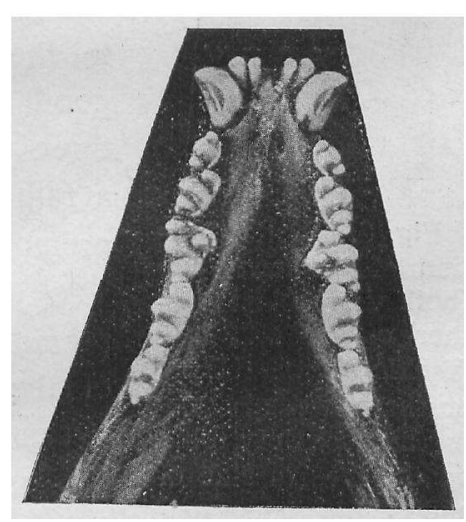

Fig. 4. Anterior portion of the lower jaw of an adult Phoca hispida from the outer archipelago of the Stockholm gouvernment district showing a broad third premolar produced by the fusion of the normal tooth with an accessory tooth on its median side. The symmetry of both sides noteworthy. small one in front and another behind. The anteroposterior diameter of this tooth is only $3 \mathrm{~mm}$., but it is nevertheless provided with a double root.

The conditions presented by the specimen from Nederkalix, northern Sweden, which is reproduced in fig. 5, may be interpreted in two different ways. If the two most anterior teeth behind the 
canine are taken as first and second premolar they are undoubtedly on the right side followed by four and on the left by five teeth belonging to the same series. In such a case we should have on

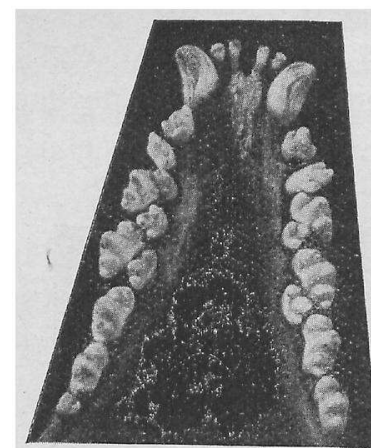

Fig. 5. Anterior portion of the lower jaw of a Phoca hispida from Nederkalix. northern Sweden showing a supernumerary second molar $\left(m_{2}\right)$ on the left side and several accessory teeth at the premolar series of both sides. the left side a second and on the right a second and a third supernumerary molar, the last of which is rather small. If it is assumed that one (most likely the second) of the anterior pair of premolar teeth on either side represents an accessory one, which may be possible and probable, because their position in the jaw is somewhat irregular, it is only the small last molar of the right side which represents a supernumerary $m_{2}$.

The occurrence of a tooth, which may be understood as a second molar has been stated a couple of times by SAHLERTZ in this species, and BATESON records similar cases for other species. In Halichoerus I have seen $\mathrm{m}^{2}$ present in the upper jaw once. The reappearance of the second molar may thus now and then take place in both jaws among Seals. An interesting thing is, that when the second molar is present, it is, at least as a rule smaller than the other molars, i. e. it reappears usually in the reduced condition.

A strange thing is that accessory teeth at the side of the normal series so often are present in Phoca hispida. As a rule these are to be seen on the median side of the regular series. Typically they sit on the inner side and somewhat behind a premolar so that they partly occupy the interspace between two members of the regular series. Fig. 6 shows one of the most simple and typical examples of such accessory teeth in a specimen from Umeå. In this case there is on either side an accessory tooth on the inner side of the second premolar and between the same and the third. The symmetry

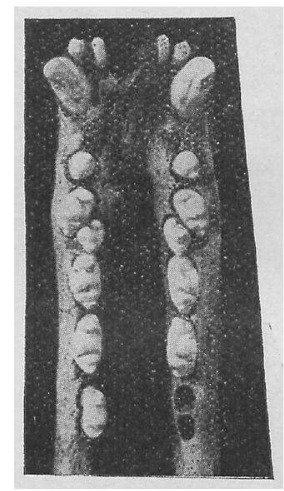

Fig. 6. Dental portion of the lower jaw (both rami broken together) of an adult $P$ hoca hispida from Umeå, northern Sweden showing an accessory tooth on the median side of and behind the second premolar. is complete on both sides. The accessory teeth have quite the same structure as the regular premolars with one cusp in front of and two small ones behind the main cusp and with double roots. They are, however, a little smaller than the teeth of the normal set.

The specimen with six incisors, which has been described above, has also on either side two accessory premolars, the anterior inside of the third premolar and between the same and the fourth; the posterior stands in the same relation to the fourth premolars and the molar (cf. fig. 1). The symmetry is almost as good as in the former case, but these accessory teeth are. only provided with three cusps. In still another (old) specimen, from Holmön, there is on either side a rather large accessory tooth with three cusps and double root behind the fourth premolar and inside the molar.

The specimen from Hudiksvall, already mentioned for its canine-like first premolar and its small $m_{2}$, has not less than three accessory teeth on the inside of the normal series. The most anterior of these is found at the interspace between the second and third, the next between third and fourth premolars and the last inside the first molar (fig. 2). The most anterior is a little irregular with four cusps and simple root, the others have three cusps each. The middle one has double root, the hindmost only a simple stumpy root. Of interest is that in spite of the aberrant structures in this case as well as in the foregoing the symmetry between right and left side is perfect.

In the specimen from Nederkalix mentioned above (fig. 5), the two most anterior teeth of the premolar series sit in the same row, but it appears nevertheless probable, that one of them (the posterior) is an accessory tooth. If this is so, there are still two accessory teeth in the usual situation on the inside, viz. between second and third, and between third and fourth premolars. All these are tricuspid with simple roots. The symmetry is perfect. Strange to say the only case (with one exception) in which symmetry does not prevail is concerning a specimen which has some supernumerary anomalous teeth on the outer side of the regular series. It is from Nätra in Angermanland and has outside of the first premolar of the right side an unicuspid, but double-rooted tooth. On the left side 
in the same position there are two teeth. The anterior of these would look exactly like a canine, if it had not had on the inner side a small extra cusp. The posterior of these extra teeth is unicuspid. On the whole these extra teeth on the outer side of the normal teeth have an appearance, which widely differs from that of the accessory teeth of the inner side. They look very simple and give the impression of rudiments. They are, however, far too large to represent retained rudiments from the milkdentition, and their position outside the first premolar, which is not known to have any milkpredecessor, speaks also against such a hypothese. From their irregular appearance etc. it is most likely that they are pure anomalies. The accessory teeth on the inner side of the regular set are as well similar inter se as at the same time like the ordinary teeth in their general structure. In consequence of this and of their position they almost give the impression of being premature members of a succeeding dentition.

The above described phenomena, the reappearance of phylogenetically lost teeth, the concrescence as well longitudinally as transversely of teeth etc. represent of course anomalies and must thus not be overrated, but on the other hand they are apt to show the possibilities in the organic evolution, and such things that are anomalous once, might become regular occurrences in other instances.

All jaws showing these anomalies are of Phoca hispida from the northern parts of the Baltic, i. e. from the Bothnic Bay. The Seals of this species living in this region have as a rule thicker and more robust teeth than Arctic members of the same species. It is not unusual to see jaws of Ph. hispida from the Bothnic Bay which show teeth almost similar to those of $P h$. vitulina. The transverse diameter of the thickest premolars in the present set of jaws varies between 4,5 and $6 \mathrm{~mm}$. In consequence of their size the teeth very often have an oblique position in the jaw just as is the case in $P h$. vitulina. This appears to indicate, that the teeth are of more importance to the Ringed Seals of the Baltic than to those of the Arctic Sea. In consequence of this the reduction of the dentition has been checked, and, more than that, there seems to be even a stimulus to a better and stronger development of the teeth, which in its turn may have provoked the great variation. 